\title{
Characterization of a beta-glucosidase from Bacillus licheniformis and its effect on bioflocculant degradation
}

\author{
Zhen Chen ${ }^{1,2,3}$, Tong Meng ${ }^{1,2}$, Zhipeng Li ${ }^{1,2}$, Peize Liu ${ }^{1,2}$, Yuanpeng Wang ${ }^{1,2}, \mathrm{Ning} \mathrm{He}^{1,2^{*}}$ and Dafeng Liang ${ }^{4,5^{*}}$
}

\begin{abstract}
Bacillus licheniformis CGMCC 2876, an aerobic spore-forming bacterium, produces a polysaccharide bioflocculant that is biodegradable and harmless. The present study determined that $\beta$-glucosidase played a negative role in bioflocculant synthesis. The gene encoding $\beta$-glucosidase was cloned and expressed in Escherichia coli BL21. This gene consists of $1437 \mathrm{bp}$ and encodes 478 amino acid residues. The recombinant $\beta$-glucosidase (Bgl.bli1) was purified and showed a molecular mass of $53.4 \mathrm{kDa}$ by SDS-PAGE. The expression and reaction conditions of Bgl.bli1 were optimized; the activity of $\beta$-glucosidase reached a maximum at $45.44 \mathrm{U} / \mathrm{mL}$. Glucose clearly inhibited the activity of $\beta$-glucosidase. The purified recombinant Bgl.bli1 hydrolysed polysaccharide bioflocculant in vitro and synergised with other cellulases. The ability of Bgl.bli1 to hydrolyse polysaccharide bioflocculant was the reason for the decrease in flocculating activity and indicated the utility of this enzyme for diverse industrial processes.
\end{abstract}

Keywords: $\beta$-Glucosidase, Heterologous expression, Polysaccharide bioflocculant, Bacillus licheniformis

\section{Introduction}

Beta-glucosidase ( $\beta$-D-glucoside glucohydrolase, EC 3.2.1.21) catalyses the hydrolysis of $\beta$-glucosidic linkages of various glycosides and oligosaccharides to form a debranched or shorter oligosaccharide and glucose. In combination with endoglucanases (EC 3.2.1.4) and cellobiohydrolases (EC 3.2.1.91), $\beta$-glucosidase can hydrolyse cellulose to glucose (Béguin and Aubert 1994). $\beta$-Glucosidase more efficiently stimulates and regulates cellulose hydrolysis by relieving cellobiose inhibition; it is thus a key rate-limiting enzyme of the cellulose-hydrolysing system (Bhatia et al. 2002). $\beta$-Glucosidase is distributed throughout a broad range of organisms, including microbes, plants, and animals (Chang et al. 2008; Knight and Dick 2004). Some studies have been conducted to

\footnotetext{
*Correspondence: hening@xmu.edu.cn; Idfit@126.com

${ }^{1}$ Department of Chemical and Biochemical Engineering, College

of Chemistry and Chemical Engineering, Xiamen University,

Xiamen 361005, China

${ }^{4}$ Guangxi State Farms Sugar Industrial Group Company Limited, Guangxi

Sugarcane Industry R\&D Center, Nanning 530002, Guangxi,

People's Republic of China

Full list of author information is available at the end of the article
}

isolate novel $\beta$-glucosidases from the genus Bacillus, which represents one of the most important groups of bacteria not only for its production of commercially valuable enzymes but also in the study of the mechanism of extracellular polymer secretion (Chamoli et al. 2016; Khan and Husaini 2006; Zahoor et al. 2011).

Bacillus licheniformis CGMCC 2876, a Gram-positive and spore-forming bacterium, produces a flocculating agent that is widely used in industrial processes, including wastewater refinement, downstream treatments, and food-related and fermentation processes (Xiong et al. 2010; Zhuang et al. 2012). The bioflocculant from B. licheniformis CGMCC 2876 is an extracellular polymer mainly composed of polysaccharide $(89 \%$, wt/wt). In the latter phase of polysaccharide fermentation, the flocculating activity decreases because of the degradation of this bioflocculant. At the same time, a gene encoding $\beta$-glucosidase (Bgl.bli1) in a bioflocculant-producing clone was predicted to be involved in polysaccharide bioflocculant dissimilation (Yan et al. 2013). The present study describes the cloning, heterologous expression and biochemical characterization of this $\beta$-glucosidase. Moreover, the relation between $\beta$-glucosidase and 
polysaccharide bioflocculant was further explored. This report is the first of the hydrolysis of a polysaccharide bioflocculant by $\beta$-glucosidase.

\section{Materials and methods}

Strains, media, and culture conditions

Bacillus licheniformis CGMCC 2876 was previously isolated by our laboratory. EPS medium contained $(\mathrm{g} / \mathrm{L})$ sucrose or glucose, 13.6; urea, 2.36; $\mathrm{MgSO}_{4}, 0.05$; $\mathrm{KH}_{2} \mathrm{PO}_{4}, 0.04 ; \mathrm{K}_{2} \mathrm{HPO}_{4}, 0.4$; and yeast extract, 0.5. The initial $\mathrm{pH}$ of the EPS medium was adjusted to 7.2. To produce bioflocculant, conical flasks were incubated at $37^{\circ} \mathrm{C}$ on a rotary shaker at $200 \mathrm{rpm}$ for $72 \mathrm{~h}$. Escherichia coli BL21 (DE3) cultured on LB medium was used to express Bgl.bli1. Media for E. coli BL21 (DE3) transformed with pEASY-E1 was supplemented with $100 \mu \mathrm{g} / \mathrm{mL}$ ampicillin.

\section{PCR amplification and cloning of $b g l$}

The genomic DNA from B. licheniformis CGMCC 2876 was extracted using a genomic DNA extraction kit (Omega, China). The gene ( $b g l)$ encoding $\beta$-glucosidase was amplified from the template genomic DNA via a polymerase chain reaction (PCR) using DNA polymerase (Trans, China). The sequences of the oligonucleotide primers used for this gene cloning were based on the DNA sequence of $\beta$-glucosidase (GenBank Accession Number: JQ773458). Forward (5'-ATGGCGA GACAAACGTGG-3') and reverse (5'-TTATTTATAC CGGAATTCCTCTGT-3') primers were designed and synthesized by Sangon (China). The amplified DNA fragment was purified and cloned into a pEASY-E1 $6 \times$ His fusion vector using a pEASY-E1 Expression Kit (Trans, China).

\section{Expression and purification of Bgl.bli1}

The resulting recombinant $\mathrm{pEASY}-b g l$ was transformed into E. coli BL21 (DE3). E. coli BL21 (DE3) harbouring the recombinant plasmid was grown in an LB-ampicillin medium at $37{ }^{\circ} \mathrm{C}$ until the $\mathrm{OD}_{600}$ of the culture reached 0.4-0.6, at which point the protein expression was induced through the addition of $0.25-2 \mathrm{mM}$ isopropyl $\beta$-D-1-thiogalactopyranoside (IPTG). To obtain maximum expression of the recombinant $\beta$-glucosidase, different induction times and concentrations of IPTG were tested. Bacterial cells were incubated for a further $6 \mathrm{~h}$ at $37^{\circ} \mathrm{C}$ and then harvested via centrifugation at $6000 \mathrm{rpm}$ for $10 \mathrm{~min}$ at $4{ }^{\circ} \mathrm{C}$. The cells were washed twice with a solution consisting of $1 \%$ Triton X-100 (pH 7.0), $50 \mathrm{mM}$ sodium phosphate and $5 \mathrm{mM}$ EDTA. They were then resuspended in $50 \mathrm{mM}$ sodium phosphate ( $\mathrm{pH}$ 7.0). The cells were disrupted via ultrasonication (Thermo, MA,
USA). The debris and intact cells were removed via centrifugation at $9000 \mathrm{rpm}$ for $10 \mathrm{~min}$ at $4{ }^{\circ} \mathrm{C}$ to obtain the crude cell extract. The His tag was purified using ProteinIso ${ }^{\mathrm{TM}} \mathrm{Ni}-\mathrm{NTA}$ Resin (Trans, China). The homogeneity of the protein was assessed using 10\% SDS-PAGE.

\section{Enzyme activity and protein concentration assays}

Bgl.bli1 activity was determined by measuring the hydrolysis of p-nitrophenyl- $\beta$-D-glucopyranoside (pNPG) according to the method in a previous study (Shi et al. 2017). The activity of crude enzyme in the intracellular extract was defined in units per $\mathrm{mL}$ of culture. Protein concentrations were determined with a Bio-Rad protein Assay Kit (Bio-Rad, USA) by measuring $\mathrm{A}_{595}$ and comparing the results to those of bovine serum albumin standards.

\section{Determination of flocculating activity}

Flocculating activity was measured using kaolin-clay suspensions as an indicator as described previously (Xiong et al. 2010).

\section{Quantification of reducing sugars}

Reducing sugar concentrations were determined by the 3,5-dinitrosalicylic acid (DNS) method. Briefly, $1 \mathrm{~mL}$ of appropriately diluted sample solution and $3 \mathrm{~mL}$ of DNS reagent were mixed, and the mixture was heated to $99^{\circ} \mathrm{C}$ for $5 \mathrm{~min}$ in a boiling water bath. Finally, the reducing sugar concentration was calculated from the OD measured at $520 \mathrm{~nm}$ and the standard curve. All assays were performed in triplicate, and average values were reported.

\section{Enzyme characterization}

The purified recombinant Bgl.bli1 was characterized as a function of temperature, $\mathrm{pH}$, metal ions and glucose. The optimal temperature for enzyme activity was determined over a temperature range from 30 to $90{ }^{\circ} \mathrm{C}$ at $\mathrm{pH}$ 7.0 using standard assay conditions. To determine the optimum $\mathrm{pH}$ for the recombinant enzyme, we measured $\beta$-glucosidase activity over a $\mathrm{pH}$ range from 4.0 to 11.0 in increments of $1 \mathrm{pH}$ unit at $50{ }^{\circ} \mathrm{C}$ using standard assay conditions. The effects of metal ions on enzyme activity were studied by adding $10 \mathrm{mM} \mathrm{CuSO}_{4}, \mathrm{MgSO}_{4}, \mathrm{ZnSO}_{4}$, $\mathrm{CaCl}_{2}, \mathrm{NaCl}, \mathrm{KCl}$ and $\mathrm{MnSO}_{4}$ to separate assay trials. The effect of glucose on enzyme activity was studied by adding 10, 20, 30 and $40 \%(w / w)$ glucose. The effects of temperature, $\mathrm{pH}$, metal ions and glucose on enzyme stability were determined by incubating the enzyme under different conditions for periods as long as $0.5 \mathrm{~h}$ and then assaying the residual activity. 


\section{Results}

Effect of $\beta$-glucosidase on the flocculating activity

Bacillus licheniformis CGMCC 2876 was cultured in a fermentation medium for the production of polysaccharide bioflocculant using sucrose and glucose as carbon sources, and the flocculating activity of the fermentation broth, enzyme activity of $\beta$-glucosidase and concentration of reducing sugars were determined during the fermentation period (Fig. 1). When sucrose was used as the substrate, the flocculating activity decreased sharply after $20 \mathrm{~h}$ and decreased by as much as half. In contrast, the total enzyme activity of $\beta$-glucosidase increased dramatically and reached $16.9 \mathrm{U} / \mathrm{mL}$. The reducing sugar concentration also increased. However, when glucose was used as the substrate, the flocculating activity increased gradually in the late stage, and the changes in the total
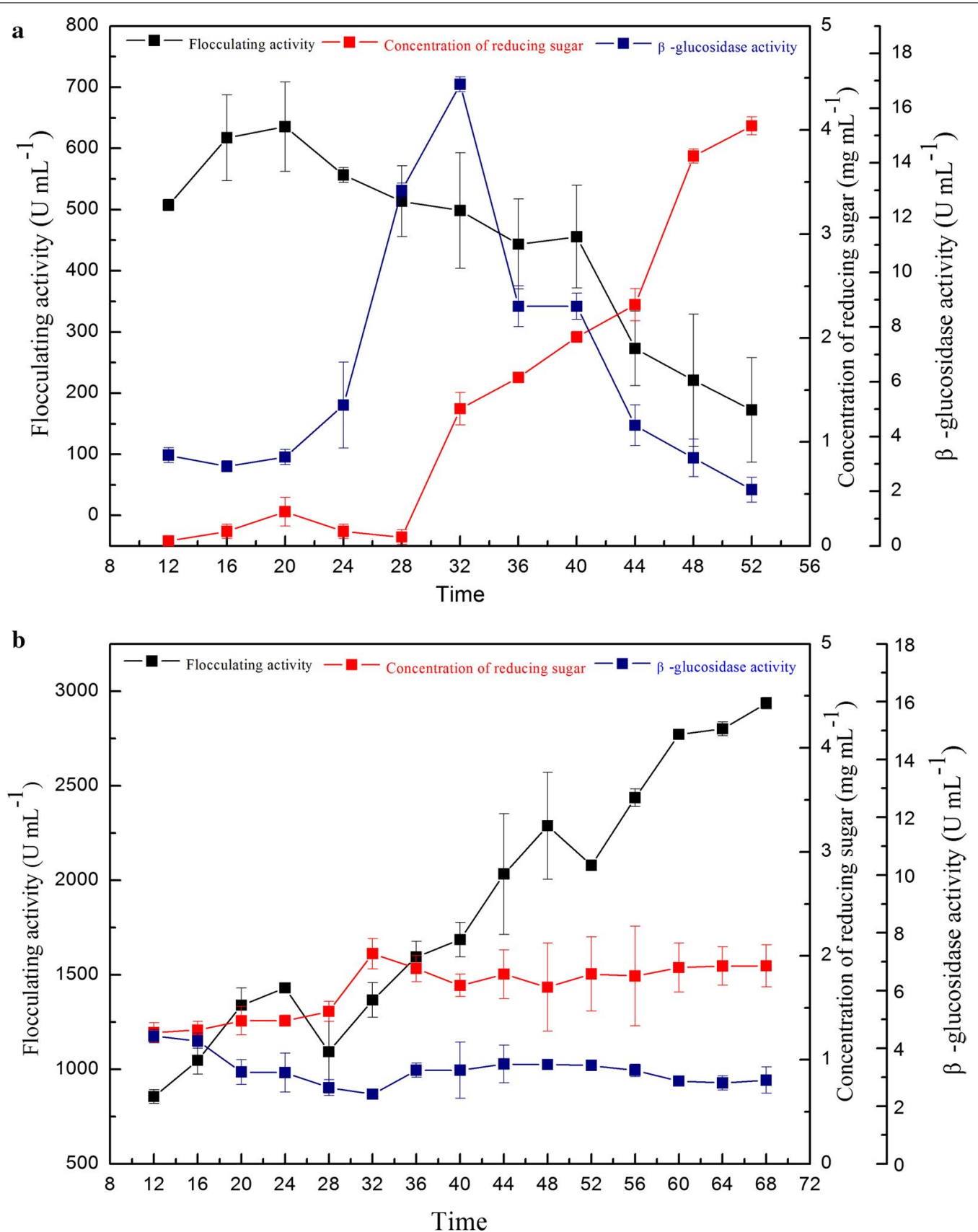

Fig. 1 Flocculating activity, $\beta$-glucosidase activity and the concentration of reducing sugars $\mathbf{a}$ using sucrose as substrate and $\mathbf{b}$ using glucose as substrate 
enzyme activity of $\beta$-glucosidase and the reducing sugar concentration in fermentation broth were not significant. The $\beta$-glucosidase activity was maintained at a lower level (2-4 $\mathrm{U} / \mathrm{mL})$. These results suggested that $\beta$-glucosidase activity had a negative effect on flocculating activity. The $\beta$-glucosidase was then expressed and purified to further study its functional characteristics.

\section{Overexpression and purification of recombinant Bgl.bli1}

The $\beta$-glucosidase gene $(b g l)$, consisting of $1437 \mathrm{bp}$, was amplified from the genome of $B$. licheniformis CGMCC 2876 by PCR using the sequence-specific primers described above. Purified PCR product was ligated to $p E A S Y$-E1, and the resulting plasmid was transformed into E. coli BL21. Positive clones were identified by the blue and white screening method. The presence of the $b g l$ gene in the recombinant strain was further confirmed by PCR and complete nucleotide sequencing of the insert. The results confirmed that the cloned fragment encoded Bgl.bli1 from B. licheniformis. To maximize the yield of the fusion protein in a soluble form, different induction conditions were investigated. Induction with $0.5 \mathrm{mM}$ IPTG at $37{ }^{\circ} \mathrm{C}$ and cultivation for $5 \mathrm{~h}$ after induction produced the maximum level of soluble, active fusion enzyme, reaching as high as $45.44 \mathrm{U} / \mathrm{mL}$. The recombinant enzyme was purified by Ni-NTA resin, and the supernatant from cell lysates as well as purified protein were then applied to SDS-PAGE (Fig. 2). The molecular mass of the His-Bgl.bli1, calculated via its amino acid sequence, was $53.4 \mathrm{kDa}$ and was identical to the mass obtained by SDS-PAGE. In addition, recombinant Bgl. bli1 represents $46.5 \%$ of the total soluble protein in the E. coli lysate. This high expression level of the protein in soluble form improves its applicability for industry.

\section{Characterization of recombinant Bgl.bli1}

The activity of the purified recombinant Bgl.bli1 was examined over a $\mathrm{pH}$ range from 4.0 to 11.0 at $50{ }^{\circ} \mathrm{C}$ using phosphate-citric acid buffer. The activity of the recombinant Bgl.bli1 was optimal at $\mathrm{pH} 7.0$ (Fig. 3a). The enzyme activity remained at low levels in acidic solutions, 14.3 and $4.7 \%$ of maximal activity at $\mathrm{pH} 5$ and 4, respectively. However, enzyme activity decreased greatly at $\mathrm{pH} 8.0$ and decreased to $56.0 \%$ of its maximal level at $\mathrm{pH}$ 9.0. These results suggested that Bgl.bli1 is fit for application in neutral or alkaline solutions. Bgl.bli1 showed poor activity at $30{ }^{\circ} \mathrm{C}$. The enzyme activity increased with increasing temperature and reached a maximum at $60{ }^{\circ} \mathrm{C}$. When the temperature was $80{ }^{\circ} \mathrm{C}$, the enzyme retained approximately $80 \%$ of its maximum activity, which suggested that Bgl. bli1 is a thermotolerant enzyme with a wide application scope.

The effect of metal ions on recombinant Bgl.bli1 activity was also investigated (Table 1). Bgl.bli1 activity was dramatically increased by the presence of $\mathrm{Zn}^{2+}, \mathrm{Mg}^{2+}$ and $\mathrm{Mn}^{2+}$ ions, while $\mathrm{Cu}^{2+}$ and $\mathrm{Ca}^{2+}$ significantly inactivated the $\beta$-glucosidase. Bgl.bli1 activity was not affected by $10 \mathrm{mM} \mathrm{Na}^{+}$and $\mathrm{K}^{+}$ions. These results suggested that the active catalytic domain of the Bgl.bli1 protein contains a divalent metal ion binding site. These properties differed from those of other $\beta$-glucosidases from various sources. Jiang et al. (2011) reported that a $\beta$-glucosidase, Bgl1E, from uncultured soil microorganisms did not contain a metal ion binding site. (Mallek-Fakhfakh and Belghith 2016) found that a $\beta$-glucosidase, Bgl.tls, from Talaromyces thermophilus was not affected by the $\mathrm{Ca}^{2+}, \mathrm{Co}^{2+}, \mathrm{Mg}^{2+}$ and $\mathrm{Mn}^{2+}$ divalent metal ions.

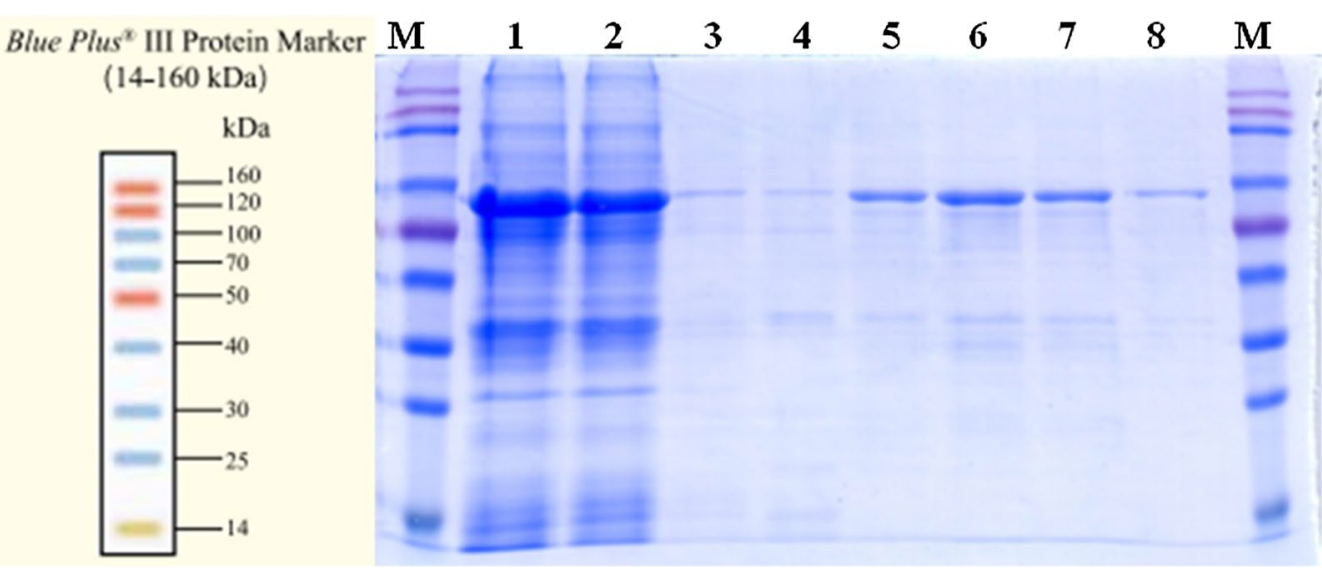

Fig. 2 10\% SDS-PAGE of Bgl.bli1. Lanes 1 and 2, total protein of cells induced with IPTG; lanes 3-8, purified recombinant Bgl.bli1 

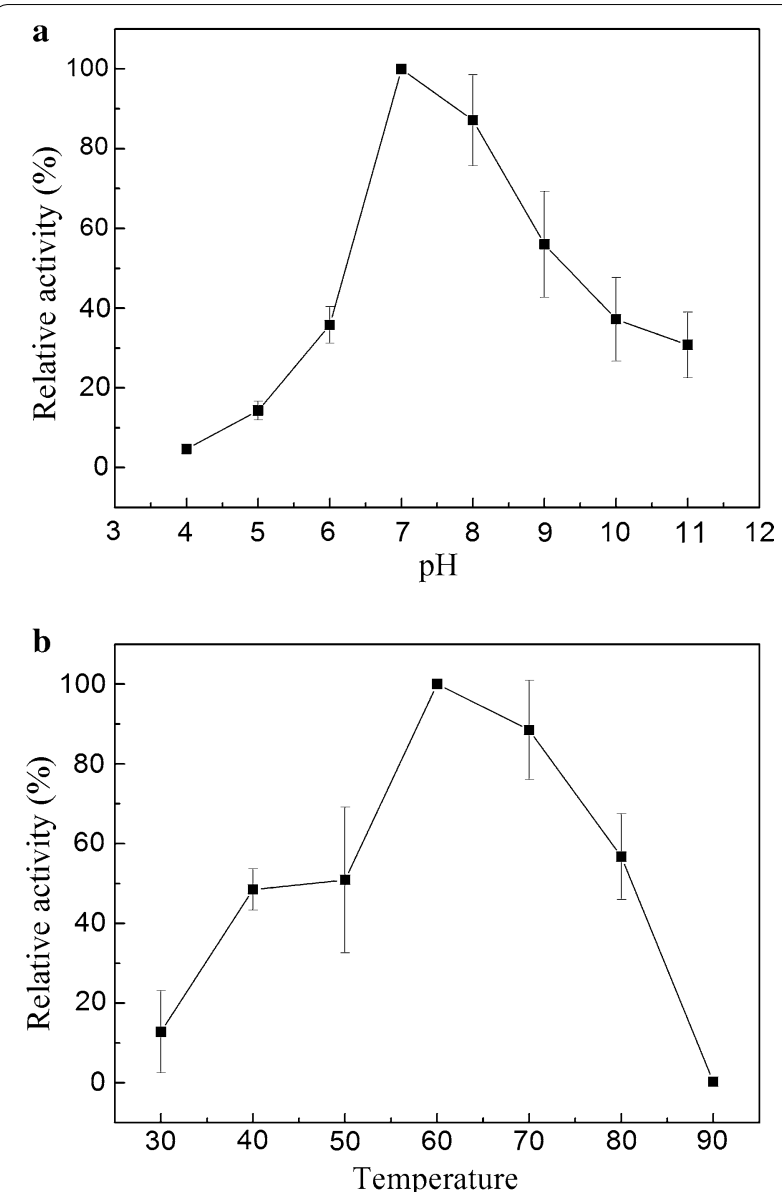

Fig. 3 Effects of $\mathbf{a} \mathrm{pH}$ and $\mathbf{b}$ temperature on the activity of purified recombinant Bgl.bli1

Table 1 Effects of metal ions on the activity of purified recombinant Bgl.bli1

\begin{tabular}{lc}
\hline Solution $(\mathbf{1 0} \mathbf{~ m})$ & Relative activity \\
\hline $\mathrm{NaCl}$ & $100.5 \pm 3.12$ \\
$\mathrm{KCl}$ & $94.2 \pm 2.12$ \\
$\mathrm{CaCl}$ & \\
$\mathrm{MnSO}_{4}$ & $80.7 \pm 10.62$ \\
$\mathrm{ZnSO}_{4}$ & $140.9 \pm 0.9$ \\
$\mathrm{CuSO}_{4}$ & $125.3 \pm 14.87$ \\
$\mathrm{MgSO}_{4}$ & $69.4 \pm 1.42$ \\
\hline
\end{tabular}

\section{The effect of glucose on enzyme activity}

Generally speaking, glucose can inhibit the activity of $\beta$-glucosidase (Singhania et al. 2013). The inhibitory effect of glucose on the activity of purified recombinant Bgl.bli1 was assayed with various concentrations of glucose. Table 2 shows that Bgl.bli1 activity was gradually
Table 2 Effect of glucose on the activity of purified recombinant Bgl.bli1

\begin{tabular}{llllll}
\hline Glucose concentration $(\mathrm{w} / \mathrm{w})(\%)$ & 0 & 10 & 20 & 30 & 40 \\
Enzyme activity $(\mathrm{U} / \mathrm{mL})$ & 53.31 & 26.26 & 20.87 & 8.67 & 0.62 \\
Relative activity $(\%)$ & 100 & 49.26 & 39.10 & 16.26 & 0
\end{tabular}

repressed with increasing glucose concentration, which revealed that glucose competitively inhibited the $\beta$-glucosidase hydrolysis of pNPG. The results confirmed that Bgl.bli1 is a glucose-sensitive glycosidase, which was beneficial to bioflocculant production in B. licheniformis CGMCC 2876 because the yield and flocculating activity gradually increased when glucose was used as the carbon source (Fig. 1b).

\section{Hydrolysis of polysaccharide bioflocculant by Bgl.bli1 in vitro}

To further verify the hydrolysis of polysaccharide bioflocculant by $\beta$-glucosidase, the exopolysaccharide fermentation broth used sucrose or glucose as substrates, and its purified products were treated with crude recombinant Bgl.bli1. The loss of flocculating activity is shown in Fig. 4. When sucrose and glucose are each used as substrates, the flocculating activities of polysaccharide fermentation broth declined by 25.6 and $12.7 \%$, respectively. However, the flocculating activities of purified polysaccharide bioflocculant only decreased by approximately $8 \%$. The different results among samples might be caused by the other glycoside hydrolase in the fermentation broth, which played synergetic roles with $\beta$-glucosidase in the hydrolysis of polysaccharide bioflocculant. A commercialized endoglucanase was also used to dispose of the polysaccharide bioflocculant, giving results very

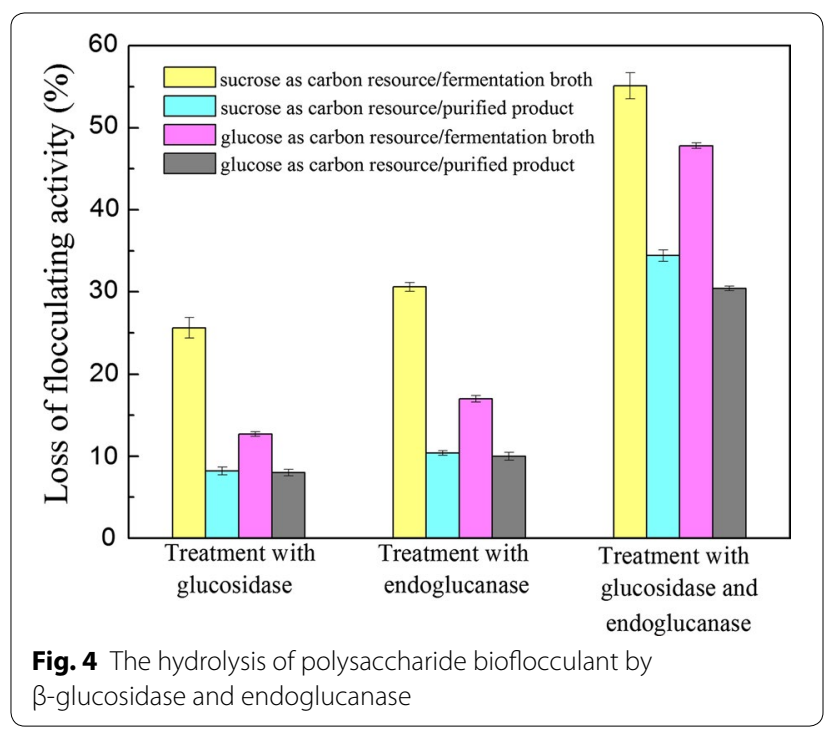


similar to those of Bgl.bli1. Furthermore, an enzyme mixture of Bgl.bli1 and endoglucanase was utilized to hydrolyse the polysaccharide bioflocculant, resulting in much greater loss of flocculating activity than when treated with individual enzymes. Bgl.bli1 showed a strong synergistic effect on endoglucanase, with the loss of flocculating activity of purified polysaccharide bioflocculant reaching as high as $30 \%$. The above results suggested that the hydrolysis of the polysaccharide bioflocculant produced by $B$. licheniformis could be improved by the addition of heterologously expressed Bgl.bli1. In other words, Bgl.bli1 played a negative role in the flocculating activity.

\section{Discussion}

Polysaccharide bioflocculant generally has the advantages of high flocculating activity and good thermal stability. However, the flocculating activity of polysaccharide bioflocculant rapidly declines in late fermentation stages. Many polysaccharide bioflocculant-producing strains, including Virgibacillus sp. (Cosa et al. 2011), Bacillus firmus (Salehizadeh and Shojaosadati 2002) and Enterobacter aerogenes (Lu et al. 2005), behave in this manner. Intracellular or extracellular glucoside hydrolase partially or completely hydrolyses the polysaccharide chain (Meng et al. 2015), which could affect the active components of flocculant and result in a decline of flocculating activity. $\beta$-Glucosidase was probably a related enzyme that caused the loss of the flocculating activity because of the hydrolysis of the non-reduced end of the cello-oligosaccharide involved in flocculation or because of the relief of substrate inhibition of other cellulases. However, the activity of $\beta$-glucosidase was maintained at a low level when sucrose was replaced as the carbon source by glucose. At the same time, the flocculating activity increased continuously in the late stages, instead of decreasing. The result showed that $\beta$-glucosidase might be inhibited by glucose in the medium without significantly affecting polysaccharide flocculant activity. This phenomenon was also reported in the transformation of cellulose into glucose (Tokuda et al. 2009). As the glucose concentration in product increased, the activity of $\beta$-glucosidase was inhibited, resulting in reduced cellulose degradation. We therefore inferred that $\beta$-glucosidase was involved in the degradation of polysaccharide bioflocculant.

In this study, we successfully cloned the $b g l$ gene from bioflocculant-producing $B$. licheniformis and achieved a high level of extracellular expression of its protein product in E. coli. This strategy can be used for the economical production of $\beta$-glucosidase. Further, the recombinant Bgl.bli1 was purified and biochemically characterized in detail for further industrial applications.
More importantly, the relation between $\beta$-glucosidase and polysaccharide bioflocculant was explored. The $\beta$-glucosidase was deemed to decrease the flocculating activity of bioflocculant produced by $B$. licheniformis CGMCC 2876 because of the degradation of polysaccharide bioflocculant. The recombinant Bgl-bli1 showed a strong synergistic effect with an endoglucanase in the hydrolysis of polysaccharide bioflocculant. This study demonstrated that Bgl.bli1 had a negative effect on polysaccharide bioflocculant production when sucrose was used as the carbon source, which would not be a problem when glucose is used as the carbon source, because of glucose sensitivity. Polysaccharide bioflocculant production might be enhanced by knocking out the $b g l$ gene. This new discovery will provide fermentation strategies for polysaccharide bioflocculant production by $B$. licheniformis.

\section{Abbreviations}

PCR: polymerase chain reaction; IPTG: isopropyl $\beta$-D-1-thiogalactopyranoside; PNPG: p-nitrophenyl- $\beta$-D-glucopyranoside; DNS: 3,5-dinitrosalicylic acid.

\section{Authors' contributions}

ZC, NH, YPW and DFL designed the experiments. ZC, TM and ZPL preformed the experiments. ZC, PZL, NH and DFL analyzed the results. ZC, TM, PZL and $\mathrm{NH}$ wrote the manuscript which was reviewed and approved by all authors. All authors read and approved the final manuscript.

\section{Author details}

${ }^{1}$ Department of Chemical and Biochemical Engineering, College of Chemistry and Chemical Engineering, Xiamen University, Xiamen 361005, China.

${ }^{2}$ The Key Lab for Synthetic Biotechnology of Xiamen City, Xiamen University, Xiamen 361005, People's Republic of China. ${ }^{3}$ College of Life Sciences, Xinyang Normal University, Xinyang 464000, Henan, China. ${ }^{4}$ Guangxi State Farms Sugar Industrial Group Company Limited, Guangxi Sugarcane Industry R\&D Center, Nanning 530002, Guangxi, People's Republic of China. ${ }^{5}$ Guangdong Key Lab of Sugarcane Improvement and Biorefinery, Guangzhou Sugarcane Industry Research Institute, Guangzhou 510316, Guangdong, People's Republic of China.

\section{Acknowledgements}

Not applicable.

Competing interests

The authors declare that they have no competing interests.

Availability of data and materials

All data generated or analysed during this study are included in this published article.

Consent for publication

Not applicable.

Ethics approval and consent to participate

Not applicable.

\section{Funding}

This work was financially supported by the National Natural Science Foundation of China $(51378444,21676221)$, the University of Science and Technology in Fujian Province in the cooperative major project (2015H6004) and Guangxi special funds project for Bagui scholars. 


\section{Publisher's Note}

Springer Nature remains neutral with regard to jurisdictional claims in published maps and institutional affiliations.

Received: 18 September 2017 Accepted: 29 October 2017

Published online: 06 November 2017

\section{References}

Béguin P, Aubert J-P (1994) The biological degradation of cellulose. FEMS Microbiol Rev 13(1):25-58

Bhatia Y, Mishra S, Bisaria VS (2002) Microbial ß-glucosidases: cloning, properties, and applications. Crit Rev Biotechnol 22(4):375-407

Chamoli S, Kumar P, Navani NK, Verma AK (2016) Secretory expression, characterization and docking study of glucose-tolerant $\beta$-glucosidase from $B$. subtilis. Int J Biol Macromol 85:425-433

Chang M-Y, Kao H-C, Juang R-S (2008) Thermal inactivation and reactivity of $\beta$-glucosidase immobilized on chitosan-clay composite. Int J Biol Macromol 43(1):48-53

Cosa S, Mabinya LV, Olaniran AO, Okoh OO, Bernard K, Deyzel S, Okoh Al (2011) Bioflocculant production by Virgibacillus sp. Rob isolated from the bottom sediment of Algoa Bay in the Eastern Cape, South Africa. Molecules 16(3):2431-2442

Jiang C, Li SX, Luo FF, Jin K, Wang Q, Hao ZY, Wu L-L, Zhao GC, Ma GF, Shen PH (2011) Biochemical characterization of two novel $\beta$-glucosidase genes by metagenome expression cloning. Biores Technol 102(3):3272-3278

Khan F, Husaini A (2006) Enhancing a-amylase and cellulase in vivo enzyme expressions on sago pith residue using Bacilllus amyloliquefaciens UMAS 1002. Biotechnology 5(3):391-403

Knight TR, Dick RP (2004) Differentiating microbial and stabilized $\beta$-glucosidase activity relative to soil quality. Soil Biol Biochem 36(12):2089-2096

Lu W-Y, Zhang T, Zhang D-Y, Li C-H, Wen J-P, Du L-X (2005) A novel bioflocculant produced by Enterobacter aerogenes and its use in defecating the trona suspension. Biochem Eng J 27(1):1-7
Mallek-Fakhfakh H, Belghith H (2016) Physicochemical properties of thermotolerant extracellular $\beta$-glucosidase from Talaromyces thermophilus and enzymatic synthesis of cello-oligosaccharides. Carbohydr Res 419:41-50

Meng D-D, Ying Y, Zhang K-D, Lu M, Li F-L (2015) Depiction of carbohydrateactive enzyme diversity in Caldicellulosiruptor sp. F32 at the genome level reveals insights into distinct polysaccharide degradation features. Mol BioSyst 11(11):3164-3173

Salehizadeh H, Shojaosadati SA (2002) Isolation and characterisation of a bioflocculant produced by Bacillus firmus. Biotech Lett 24(1):35-40

Shi X, Xie J, Liao S, WU T, Zhao LG, Ding G, Wang Z, Xiao W (2017) High-level expression of recombinant thermostable $\beta$-glucosidase in Escherichia coli by regulating acetic acid. Biores Technol 241:795

Singhania RR, Patel AK, Sukumaran RK, Larroche C, Pandey A (2013) Role and significance of beta-glucosidases in the hydrolysis of cellulose for bioethanol production. Biores Technol 127:500-507

Tokuda G, Miyagi M, Makiya H, Watanabe H, Arakawa G (2009) Digestive $\beta$-glucosidases from the wood-feeding higher termite, Nasutitermes takasagoensis: intestinal distribution, molecular characterization, and alteration in sites of expression. Insect Biochem Mol Biol 39(12):931-937

Xiong Y, Wang Y, Yu Y, Li Q, Wang H, Chen R, He N (2010) Production and characterization of a novel bioflocculant from Bacillus licheniformis. Appl Environ Microbiol 76(9):2778-2782

Yan S, Wang N, Chen Z, Wang Y, He N, Peng Y, Li Q, Deng X (2013) Genes encoding the production of extracellular polysaccharide bioflocculant are clustered on a 30-kb DNA segment in Bacillus licheniformis. Funct Integr Genom 13(4):425-434

Zahoor S, Javed M, Aftab M (2011) Cloning and expression of $\beta$-glucosidase gene from Bacillus licheniformis into E. coli BL 21 (DE3). Biologia 66(2):213-220

Zhuang X, Wang Y, Li Q, Yan S, He N (2012) The production of bioflocculants by Bacillus licheniformis using molasses and its application in the sugarcane industry. Biotechnol Bioprocess Eng 17(5):1041-1047

\section{Submit your manuscript to a SpringerOpen ${ }^{\circ}$ journal and benefit from:}

- Convenient online submission

- Rigorous peer review

- Open access: articles freely available online

- High visibility within the field

- Retaining the copyright to your article

Submit your next manuscript at $\boldsymbol{\nabla}$ springeropen.com 